\title{
INFLUENCE OF ANNEALING TREATMENT ON THE STRUCTURE AND MAGNETIC PROPERTIES OF Fe-Al-Cu-Nb-Si-B ALLOYS
}

\author{
G. Pavlík, P. Matta, P. Sovák, A. Zorkovská and M. Konč \\ Faculty of Science, P.J. Safárik University, Park Angelinum 9, 04154 Košice, Slovakia
}

In this paper we present experimental results on influence of $\mathrm{Al}$ content on the structure and saturation magnetostriction of $\mathrm{Fe}-\mathrm{Al}-\mathrm{Cu}-\mathrm{Nb}-\mathrm{Si}-\mathrm{B}$ alloys after heat treatment. Transmission electron microscopy observations confirmed the existence of nanocrystalline structure after annealing at $490^{\circ} \mathrm{C}$ and $550^{\circ} \mathrm{C}$ for all samples. The crystallization temperature of FeSi phase and the temperature at which the polycrystalline transformation starts were determined from temperature dependence of electrical resistivity. Aluminium slightly decreases the first crystallization temperature and considerably decreases the saturation magnetostriction in as-quenched state.

PACS numbers: $61.16 . \mathrm{Bg}, 75.50 . \mathrm{Kj}, 75.80 .+\mathrm{q}, 81.40 . \mathrm{Rs}$

\section{Introduction}

The nanocrystalline soft magnetic materials prepared by partial crystallization from the amorphous state were intensively investigated over the last years. Thanks to their excellent magnetic properties they are still an interesting subject of study [1]. While partial crystallization of amorphous precursor improves magnetic properties of these materials, their mechanical properties deteriorate - they become brittle. The substitution of various elements in FINEMET $\left(\mathrm{Fe}_{73.5} \mathrm{Cu}_{1} \mathrm{Nb}_{3} \mathrm{Si}_{13.5} \mathrm{~B}_{9}\right)$ gives an opportunity to improve its properties. Small amount of Al substitution lowers the coercivity of FINEMET [2].

The aim of this work is to present our experimental results on the influence of $\mathrm{Al}$ on nanocrystallization process and magnetostriction of FINEMET-type alloys.

\section{Experimental methods}

The samples of $\mathrm{Fe}_{73.5-x} \mathrm{Al}_{x} \mathrm{Cu}_{1} \mathrm{Nb}_{3} \mathrm{Si}_{13.5} \mathrm{~B}_{9}$ with $x=1,2,3,5,7$ (marked as Al1-Al7) were prepared by the melt spinning technique in form of thin ribbons. The nanocrystallization process was carried out by annealing at $490^{\circ} \mathrm{C}, 550^{\circ} \mathrm{C}$, and $650^{\circ} \mathrm{C}$ for $1 \mathrm{~h}$ in a vacuum furnace. The structure has been observed by transmission electron microscopy (TEM) operating at $100 \mathrm{kV}$. Temperature dependence of electric resistivity was measured by four-point $\mathrm{DC}$ technique in a vacuum furnace in temperature range $100-700^{\circ} \mathrm{C}$ with heating rate $10 \mathrm{~K} / \mathrm{min}$. Saturation magnetostriction $\lambda_{\mathrm{S}}$ was measured by the small angle magnetization rotation (SAMR) method. 


\section{Experimental results}

The as-quenched structure was checked by TEM and the amorphous state was confirmed for Al1, Al2, and Al7 samples. The structure of these samples after nanocrystallization was very similar to that of FINEMET, only a slight reduction of grain size could be noticed for $\mathrm{Al} 7$ sample annealed at $550^{\circ} \mathrm{C}$ (Fig. 1).

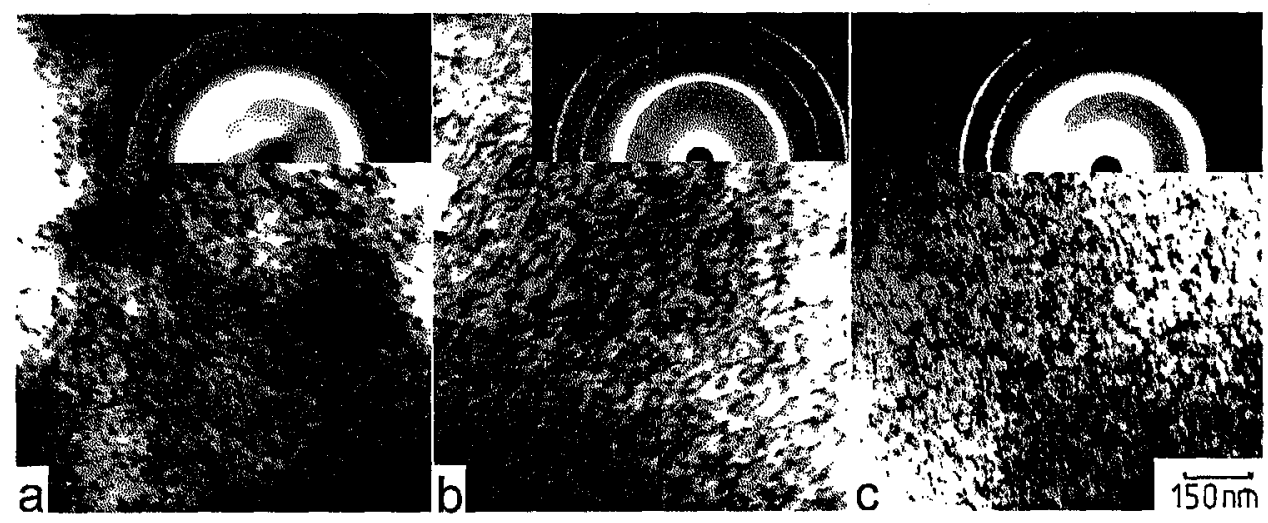

Fig. 1. TEM microphotographs and electron-diffraction patterns of All samples annealed at (a) $490^{\circ} \mathrm{C}$, (b) $550^{\circ} \mathrm{C}$, (c) Al7 sample annealed at $550^{\circ} \mathrm{C}$.

Signs of structural instability and local inhomogeneity were observed in Al3 and Al5 samples. These defects became visible through partial crystallization in as-quenched state [2] and nonhomogeneous grain size distribution after heat treatment (Fig. 2).
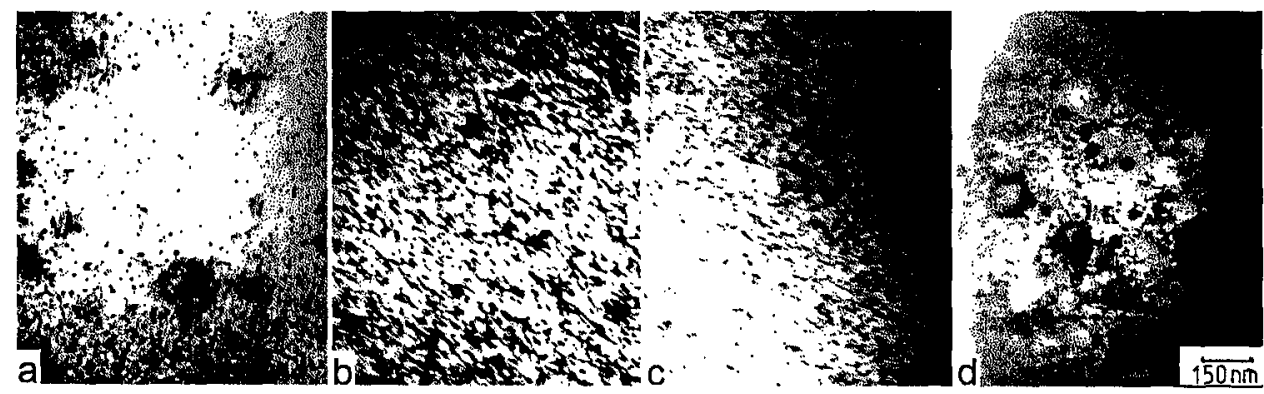

Fig. 2. TEM microphotographs of the Al3 samples annealed at (a), (b) $490^{\circ} \mathrm{C}$, (c), (d) $550^{\circ} \mathrm{C}$.

Thermoresistivity curves show that the character of the crystallization process is similar in all the samples (Fig. 3a). The steep increase in resistivity is caused by crystallization of $\mathrm{FeSi}$ (or $\mathrm{FeSiAl}$ ) phase [3] and it allows us to determine its crystallization temperature $T_{\mathrm{X} 1}$. The steepness seems to be affected by the presence of $\mathrm{Al}$ in the intergranular space or in crystalline phase [2]. The crystallization temperature $T_{\mathrm{X} 1}$ slightly decreases with $\mathrm{Al}$ content (Fig. $3 \mathrm{~b}$ ). 


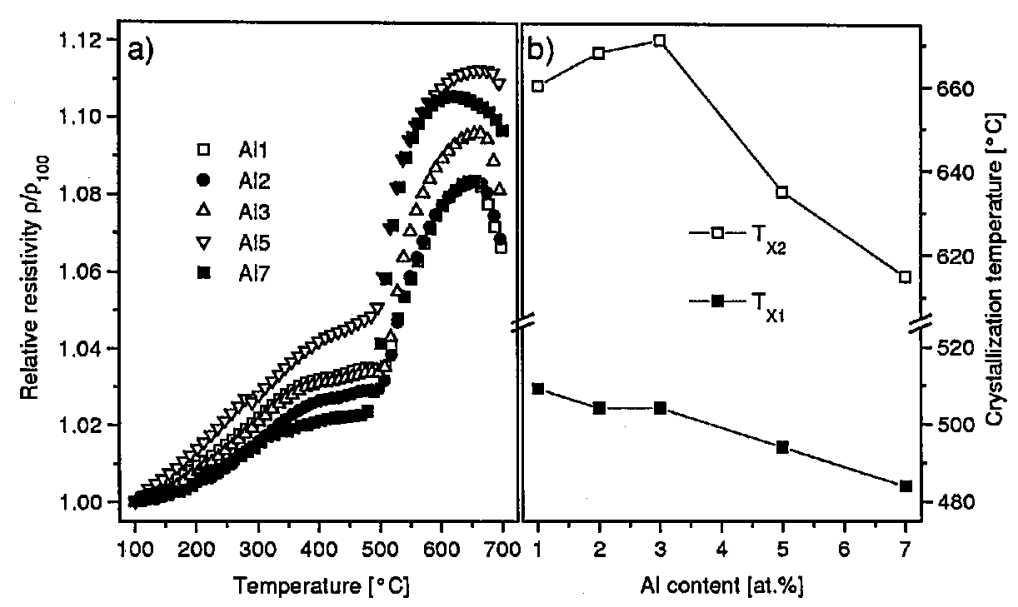

Fig. 3. (a) Thermoresistivity curves for all the samples, (b) dependences of temperatures $T_{\mathrm{X} 1}$ and $T_{\mathrm{X} 2}$ on $\mathrm{Al}$ content.

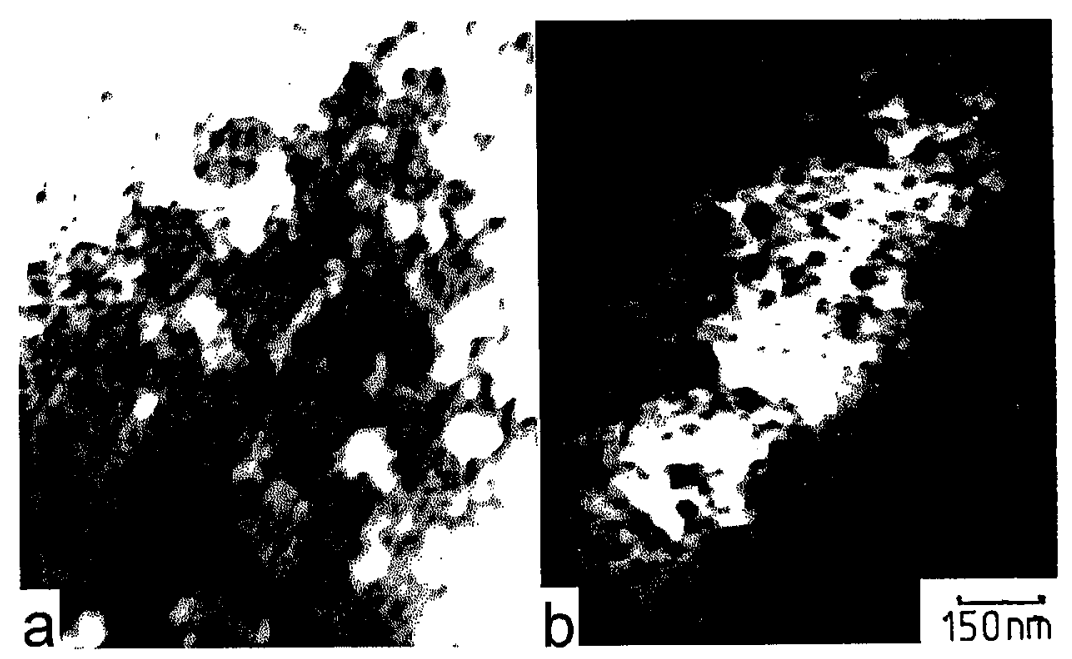

Fig. 4. TEM microphotographs of the samples annealed at $650^{\circ} \mathrm{C}$ : (a) Al3, (b) Al7.

The decrease in resistivity at higher temperatures is connected with structural transformation into polycrystalline state. According to the results obtained by TEM this transformation is accomplished in the way similar to the abnormal grain growth mechanism and therefore the coexistence of nanocrystalline structure and large polyhedral grains was observed (Fig. 4). The process like that is not typical of FINEMET [4]. The onset temperature of this process $T_{\mathrm{X} 2}$ was determined and is presented in Fig. 3b. The plateau in thermoresistivity curves for Al5 and Al7 samples observed at temperatures above $600^{\circ} \mathrm{C}$ is probably connected with the above mentioned coexistence of nanocrystalline and polycrystalline structure (Fig. 3a). 

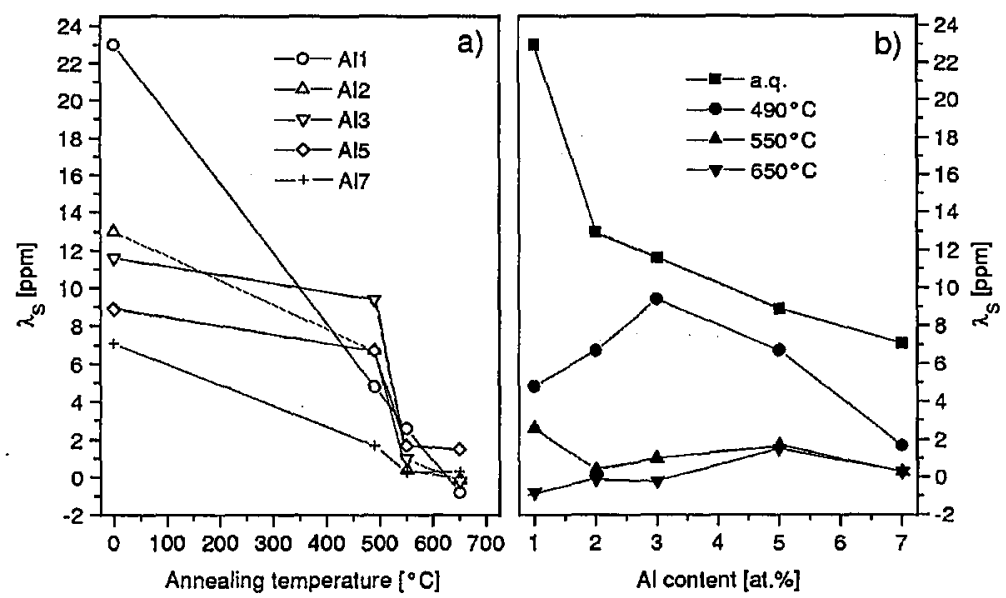

Fig. 5. (a) Dependences of saturation magnetostriction $\lambda_{S}$ on annealing temperature, (b) dependences of saturation magnetostriction $\lambda_{\mathrm{S}}$ on $\mathrm{Al}$ content.

The results obtained by magnetostriction measurement are in good agreement with structural observations. The crystallization is accompanied by the decrease in $\lambda_{\mathrm{S}}$ (Fig. 5a).

Figure $5 \mathrm{~b}$ shows that $\mathrm{Al}$ content decreases $\lambda_{\mathrm{S}}$ in as-quenched state and the nonlinearity of the decrease indicates structural inhomogeneities. After annealing at $550^{\circ} \mathrm{C}$ and $650^{\circ} \mathrm{C} \lambda_{\mathrm{S}}$ reaches nearly zero value (Fig. $5 \mathrm{~b}$ ).

\section{Conclusion}

We can conclude that in $\mathrm{Fe}_{73.5-x} \mathrm{Al}_{x} \mathrm{Cu}_{1} \mathrm{Nb}_{3} \mathrm{Si}_{13.5} \mathrm{~B}_{9}$ alloys:

- addition of $\mathrm{Al}$ deteriorates glass forming ability and $\mathrm{Al} 3$ and $\mathrm{Al} 5$ samples are partially crystallized in as-quenched state. Typical nanocrystalline structure after annealing was observed, but with nonhomogeneous grain size distribution for Al3 and Al5 samples,

- the influence of $\mathrm{Al}$ on the crystallization temperature $T_{\mathrm{X} 1}$ of $\mathrm{FeSi}(\mathrm{FeSiAl})$ phase was observed, $\mathrm{Al}$ content decreases $T_{\mathrm{X} 1}$,

- saturation magnetostriction decreases with $\mathrm{Al}$ content in as-quenched state and reaches nearly zero values after annealing at $550^{\circ} \mathrm{C}$ and $650^{\circ} \mathrm{C}$.

\section{References}

[1] J. Füzer, P. Kollár, A. Zorkovská, P. Sovák, P. Matta, M. Konč, Mater. Sci. Eng. Suppl. 228, 199 (1997).

[2] J. Moya, M.J. García, M. Vázquez, H. Sirkin, J. Phys. IV 8, PR2-237 (1998).

[3] M. Knobel, J. Schoenmaker, J.P. Sinnecker, R.S. Turtelli, R. Grössinger, W. Hofstetter, H. Sassik, Mater. Sci. Eng. A 226-228, 546 (1997).

[4] P. Matta, P. Sovák, M. Konč, T. Švec, J. Magn. Magn. Mater. 140-144, 329 (1995). 